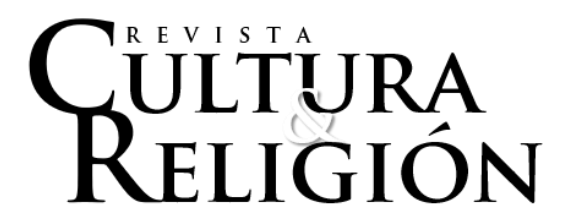

Vol. XIII, N² 2 (2019) pp. 1-29

Recibido: 11 de agosto, 2019

Aceptado: 25 de octubre, 2019

\title{
NEUROCIENCIAS Y AUTO-SECULARIZACIÓN DEL CRISTIANISMO: RESONANCIAS EN IGLESIAS CRISTIANAS CHILENAS ${ }^{1}$
}

\begin{abstract}
Neurosciences and self-secularization of christianity: resonances in chilean christian churches
\end{abstract}

por

\author{
Cecilia Dockendorff \\ Instituto de Estudios Avanzados, IDEA \\ cdocken@soles.cl
}

\author{
Javier Romero Ocampo ${ }^{* * *}$ \\ Universidad Autónoma de Chile \\ javier.romero@uautonoma.cl
}

\begin{abstract}
Resumen
El presente artículo presenta resultados de la etapa investigativa desarrollada en Chile como parte de la investigación internacional "Neurociencias y auto-secularización del cristianismo: ¿Un fundamento científico para la religiosidad?”. Dicha investigación se propuso caracterizar la forma (semánticas, organizaciones) en que comunicaciones neurocientíficas abordan fenómenos religiosos, la forma como éstas están siendo incorporadas en comunicaciones religiosas cristianas en algunos países de Europa y América, incluido Chile, y sus consecuencias para el proceso de auto-secularización de la religión. La etapa en Chile consistió en detectar resonancias por parte de personeros de iglesias cristianas a las comunicaciones estudiadas provenientes de los contextos extranjeros. No obstante, detectamos una alta resonancia positiva, se observó una significativa menor aceptación de las expresiones indicativas de mayor radicalidad de auto-secularización.
\end{abstract}

\footnotetext{
${ }^{1}$ El presente artículo es resultado de la investigación financiada por el Fondo Nacional de Desarrollo Científico y Tecnológico (FONDECYT) número 11160497 del año 2016, titulado "Neurociencias y auto-secularización del cristianismo: ¿Un fundamento científico para la religiosidad?

* Doctora en sociología. Instituto de Estudios Avanzados, IDEA, Universidad de Santiago de Chile (Santiago, Chile) https://orcid.org/0000-0002-9247-7484

** Doctor en Estudios Americanos. Facultad de Ciencias Sociales y Humanidades, Carrera de Psicología. Universidad Autónoma de Chile. (Santiago, Chile) https://orcid.org/0000-0002-6883-6061
}

Revista Cultura \& Religión Vol. XIII, 2019 № 2 (julio-diciembre)

Cómo citar este artículo: Dockendorff, C. y Romero, J. (2019). "Neurociencias y auto-secularización del cristianismo: resonancias en iglesias cristianas chilenas”. Revista Cultura \& Religión.13(2). pp. 1-29. 
Palabras clave: neurociencias, cristianismo, auto-secularización, resonancia, sociología sistémica de la religión.

\begin{abstract}
This article presents results of the research stage developed in Chile as part of the international research "Neurosciences and self-secularization of Christianity: A scientific foundation for religiosity?". This research aimed to characterize the way (semantics, organizations) in which neuroscientific communications address religious phenomena, the way in which they are being incorporated into Christian religious communications in some countries of Europe and America, including Chile, and their consequences for the process of self -secularization of religion. The stage in Chile consisted of detecting resonances by the representatives of Christian churches to the communications studied in foreign contexts. In spite we detected a high positive resonance, there was a significant lower acceptance of those expressions of greater self-secularization radicalism.
\end{abstract}

Keywords: neuroscience, Christianity, self-secularization, resonance, systemic sociology of religion.

\title{
Introducción: La investigación "Neurociencias y auto-secularización del cristianismo: ¿Un fundamento científico para la religiosidad?"
}

La investigación que origina este artículo continúa la línea investigativa abierta desde la sociología sistémica de la religión por un proyecto previo sobre la evolución de la relación ciencia-religión (Dockendorff, 2014). Allí se describieron procesos auto-reflexivos en el cristianismo, escasamente abordados anteriormente desde las ciencias sociales. Se trata del intento por parte de algunos sectores del cristianismo por responder a las exigencias cognitivas de la sociedad contemporánea modificando el lenguaje religioso, aun a costa de abandonar dogmas, creencias y tradiciones. Ello implica que el pensamiento cristiano intenta hacerse "menos religioso" para seguir siendo válido, con el fin de mantenerse vigente. Es un proceso paradójico de "des-religionización”, es decir de secularización, para, paralelamente, preservar lo central de su mensaje; lo describimos como auto-secularización. El pensamiento auto-secularizado dentro del cristianismo acepta y utiliza verdades científicas para deconstruir el lenguaje religioso dogmático-doctrinario (Dockendorff, 2016).

Observando dicho proceso de auto-secularización cristiana, detectamos una proliferación de estudios científicos que están abordando fenómenos tradicionalmente tematizados por la religión. Se trata de las neurociencias, entre ellas la neurobiología, la biología evolutiva y las ciencias cognitivas, que están estudiando diferentes experiencias descritas como religiosas y sus correlatos con procesos neuro y psicobiológicos (Brown 2009, MacNamara 2009, Newberg 2010, Brown y Strawn 2012, Golombeck 2014, Rubia

Revista Cultura \& Religión Vol. XIII, 2019 № 2 (julio-diciembre)

Cómo citar este artículo: Dockendorff, C. y Romero, J. (2019). "Neurociencias y auto-secularización del cristianismo: resonancias en iglesias cristianas chilenas”. Revista Cultura \& Religión.13(2). pp. 1-29. 
2014, 2015). Estos investigadores intentan explicar las bases neurológicas y evolutivas de una gama de experiencias subjetivas que incluyen los estados místicos, la iluminación y otros estados de conciencia asociados a la oración, meditación, contemplación, al canto y bailes religiosos, incluyendo también la tendencia humana a desarrollar y mantener creencias.

Así como la sociología no observa los contenidos teológicos sino el rol de la religión en la sociedad, las neurociencias tampoco estudian temas teológicos o doctrinales sino la relación de experiencias religiosas con procesos cerebrales y mentales. Nos preguntamos si y cómo los resultados de estas investigaciones neurocientíficas tendrían resonancia en sectores auto-secularizados del cristianismo. Efectivamente, encontramos evidencia de que las investigaciones neurocientíficas están teniendo aceptación en sectores del cristianismo (Ashbrook 1999, Drewermann 2006, 2007; Nogués 2011, 2013; Sequeiros 2012, 2013), produciéndose un emergente conjunto de producciones -organizaciones, libros, revistas, artículos- en que confluyen neurociencia y cristianismo.

Si bien con anterioridad se habían estudiado los vínculos entre el operar del cerebro humano y la práctica de meditación, particularmente la budista (Davidson et al. 2003, Lutz et al. 2006, Lutz et al. 2008, Davidson \& Lutz 2008, Varela 2009) y la meditación Zen (Austin 1999, 2011, 2014), en el cristianismo había sido más difícil porque -salvo el caso de órdenes contemplativas- en sus prácticas prima la dimensión doctrinal (dogma, ritual). No obstante, hoy encontramos una producción considerable de estudios de intersección neurocientíficacristiana, mayoritariamente en comunicaciones surgidas en países del hemisferio norte. No ocurre lo mismo en América Latina, donde la sociología de la religión ha estudiado los cambios religiosos en el cristianismo en general enfocados sobre, por ejemplo, el creciente pluralismo religioso en el contexto de la modernidad globalizada (Parker 2009, 2012; Burity 2008) o el fuerte crecimiento experimentado por las iglesias evangélicas en la región (Freston 2012; Fediakova 2007, 2012).

A partir de las producciones de intersección neurocientífica-cristiana, nos pareció plausible sostener que estaría surgiendo un nuevo tipo de relación entre ciencia y religión, superando aquellos conflictos entre racionalidades inconmensurables que se habían venido sucediendo desde el advenimiento de la modernidad. Formulamos así una hipótesis de trabajo: "Las producciones neurocientíficas son observadas en contextos cristianos autosecularizados como un aval científico, esto es, un nuevo fundamento racional para las religiones que otorgaría mayor validez, credibilidad y legitimidad a la religiosidad en el siglo XXI". Establecimos el objetivo general de la investigación como: "Caracterizar la forma en que comunicaciones neurocientíficas abordan fenómenos religiosos, la forma como éstas están siendo incorporadas en comunicaciones religiosas cristianas en algunos países de Europa y América, incluido Chile, y sus consecuencias para el proceso de auto-secularización de la religión".

Revista Cultura \& Religión Vol. XIII, 2019 Nº 2 (julio-diciembre)

Cómo citar este artículo: Dockendorff, C. y Romero, J. (2019). "Neurociencias y auto-secularización del cristianismo: resonancias en iglesias cristianas chilenas”. Revista Cultura \& Religión.13(2). pp. 1-29. 
El tema sigue siendo controversial, en tanto la racionalidad científica implícitamente cuestiona los fundamentos dogmáticos de origen sobrenatural que aun sostienen a la religión. En efecto, aceptar plenamente la racionalidad científica en el ámbito religioso puede minar las bases cristianas que se fundamentan precisamente en el dogma, la creencia y la tradición. En consecuencia, cuando ciertos sectores al interior del cristianismo están dispuestos a abandonar dichos fundamentos, estamos ante un decidido proceso de auto-secularización.

\section{Marco teórico: sociología sistémica de la religión}

Desde el punto de vista teórico, la investigación se enmarca en la teoría de sistemas sociales, inicialmente propuesta por el sociólogo alemán Niklas Luhmann (1991, 2007), basada en un paradigma sistémico-constructivista que concibe la realidad social como construida por observadores que realizan distinciones. La sociedad se observa como un sistema conformado por comunicaciones, el cual se diferencia en sistemas funcionales en la sociedad moderna, cada cual abocado sólo a resolver un problema social específico: político, económico, científico, etc. El ámbito religioso es así conceptualizado como un sistema autónomo que procesa sus propias comunicaciones en base a un código central que le permite distinguirlas de otras comunicaciones que no le pertenecen (Luhmann 2007, 2009). Esta teoría permite estudiar el fenómeno religioso desde su propia racionalidad interna, sin requerir observarlo a través de teorías de la secularización, ajenas a la propia operación del sistema religioso. Asimismo, la sociología sistémica de la religión permite dejar de lado teorías tradicionales basadas en una descripción racional de la religión (Dockendorff, 2015).

Nuestra investigación centra el análisis en un conjunto de emergentes comunicaciones desde las neurociencias y contextos cristianos que las recogen. Observamos sistémicamente las estructuras y semánticas que conforman dichas comunicaciones como producciones. Por éstas entendemos un conjunto de organizaciones, libros, revistas, artículos, videos y otros soportes que difunden las nuevas propuestas neurocientíficas y cristianas.

La observación de dichas producciones incorpora la propuesta teórico-metodológica de los acervos de valores propios, esto es, un desarrollo de la teoría de sistemas sociales para la observación de los aspectos semánticos en la comunicación (Dockendorff, 2019). El concepto de valor propio, propuesto por la cibernética de segundo orden, (Von Foerster; 1976, 2003) señala aquel conjunto de esquemas y semánticas condensadas que se repiten en un determinado sistema, indicando los contenidos diferenciales a los que las memorias de cada sistema particular recurren. Cada sistema psíquico y social participante en la comunicación lo hace desde su particular acervo de valores propios, producto de la recursividad y la evolución histórico-contextual de sus acoplamientos a la comunicación. La particularidad de estos acervos de valores propios es que muestran un efecto orientador en la comunicación, producto de repetir valores propios que permanecen y cambian en cada nivel de sistemas y en cada sistema en particular. Dicho efecto orientador varía acorde con la

Revista Cultura \& Religión Vol. XIII, 2019 № 2 (julio-diciembre)

Cómo citar este artículo: Dockendorff, C. y Romero, J. (2019). "Neurociencias y auto-secularización del cristianismo: resonancias en iglesias cristianas chilenas”. Revista Cultura \& Religión.13(2). pp. 1-29. 
profundidad de condensación del valor propio en cuestión. Valores propios profundamente condensados se hacen más difíciles de cambiar y persisten por más largo tiempo, prolongando su efecto orientador en valores propios que se condensan en grados menores de profundidad o participan en la comunicación explícita.

Para efectos de la etapa de la investigación en Chile, utilizamos, además, el concepto de resonancias, indicando una primera aceptación o rechazo a comunicaciones autosecularizadas por parte del sistema religioso en Chile, gatilladas por las producciones internacionales estudiadas. El concepto de resonancia utilizado en la teoría de sistemas sociales, refiere al operar autónomo (autopoiético) de los sistemas comunicacionales (Luhmann 1991, 2007). Lo que viene del entorno de cada sistema solo opera como irritaciones que pueden o no gatillar transformaciones en el sistema.

\section{Metodología etapa investigación internacional}

La metodología general de la investigación se definió como no experimental, descriptiva, transversal, de método mixto secuencial cualitativo-cuantitativo. El diseño específico combina el estudio bibliográfico, herramientas propias del trabajo empírico y la triangulación como método de verificación (Rossman y Wilson, 1985; Creswell 2009). La investigación general contempló tres etapas metodológicas: la primera, internacional, originalmente contemplaba estudios de caso en terreno que por motivos de fuerza mayor no pudieron realizarse siendo reemplazados por una ampliación de la investigación documental. La segunda, en Chile, utilizó metodología cualitativa en la indagación en el ámbito eclesiástico (ver infra) y cuantitativa de alcance exploratorio, no representativa, consistente en la elaboración, aplicación y análisis de una encuesta ejecutada mediante panel online dirigida a la población general.

Para la etapa internacional realizamos una extensa búsqueda de instituciones académicas, centros de investigación, autores y publicaciones (revistas indexadas) en páginas web académicas, de acuerdo a criterios de impacto, actualidad y difusión a diversos tipos de públicos. Revisado este material, pre-seleccionamos instituciones que explícita y sistemáticamente desarrollan una reflexión sobre la relación neurociencias-religiónespiritualidad. Finalmente, seleccionamos algunos centros bajo los siguientes criterios: a) Calidad y reconocimiento institucional de las producciones: centros universitarios o de investigación ligados a instituciones de prestigio. b) Grado de auto-secularización. Dejamos de lado aquellas producciones que proponen una relación ciencia-religión solo tolerante o respetuosa en base al diálogo, seleccionando las que mostraban mayor apertura de los sectores religiosos a las comunicaciones de las neurociencias; c) amplitud de impacto de su divulgación expresado en el alcance de su difusión por medio electrónicos (menciones y páginas web dedicadas al tema en distintos idiomas: español, francés e inglés) y en versiones

\section{Revista Cultura \& Religión Vol. XIII, 2019 № 2 (julio-diciembre)}

Cómo citar este artículo: Dockendorff, C. y Romero, J. (2019). "Neurociencias y auto-secularización del cristianismo: resonancias en iglesias cristianas chilenas”. Revista Cultura \& Religión.13(2). pp. 1-29. 
impresas (libros, artículos, capítulos de libros, revistas especializadas) y d) una representatividad territorial en el mundo occidental: Europa y Las Américas.

Terminamos seleccionando para un estudio en profundidad a la Universidad Pontificia de Comillas en Madrid y su Cátedra de Ciencia, Tecnología y Religión, donde confluyen teólogos y neurocientíficos españoles; el Center for Brain and Cognition de la Universidad de California; el Institute for the Biocultural Study of Religion en Boston y el Laboratorio de Cronobiología de la Universidad Nacional de Quilmes en Argentina cuyo director ha publicado ampliamente sobre el tema.

\section{Resultados etapa investigación internacional}

El principal hallazgo de la etapa metodológica internacional muestra una amplia convergencia entre las comunicaciones (semánticas, discursos) de los estudios neurocientíficos sobre fenómenos religiosos y las producciones de personeros religiosos identificados como auto-secularizados. Los elementos más destacados de esta convergencia dicen relación con los siguientes temas:

a) Las experiencias religiosas (espiritualidad) son de origen natural, no sobrenatural: Los neurocientíficos señalan que las experiencias religiosas están relacionadas de forma natural con la actividad cerebral y la evolución del cerebro humano. Concuerdan en que tanto la experiencia religiosa como la tendencia a sostener creencias pueden considerarse un universal humano. Así, el desarrollo de la espiritualidad, que pone en el centro la trascendencia o el acceso a una dimensión en que el individuo se siente en conexión con el universo (lo divino, Dios) sería un fenómeno natural. Sostienen que se puede considerar la espiritualidad como una facultad mental más, como la inteligencia, la música o el lenguaje.

Por su parte, personeros religiosos admiten que lo religioso está producido por cerebros, incluída la figura de Dios, por lo que ésta es inevitablemente humana. Afirman que, en efecto, la religión es más natural que sobrenatural pero, asimismo, más natural que artificial.

b) Religión y espiritualidad (experiencia religiosa) son distintas:

Los estudios nuerocientíficos parten de la distinción básica entre experiencias religiosas (espiritualidad) y las religiones, consideradas instituciones normativas creadas por seres humanos. Los estudios neurocientíficos no abordan los aspectos institucionales de las religiones, no obstante observan como uno de los objetivos de la religión la transformación personal a través de procesos de conciencia y autoconciencia de los individuos. Distinguen entre consciencia límbica y consciencia egoica, sosteniendo que parecen ser antagónicas, por lo que en condiciones normales 
el acceso a la consciencia límbica no resulta fácil. Pero cuando se accede a ella, la consciencia egoica desaparece y el sujeto se identifica con el Universo, la Naturaleza o su Dios. Asimismo, observan que el yo constituye un aspecto religioso clave, en tanto las prácticas religiosas dirigidas al desarrollo del sí mismo son universales.

Los personeros religiosos también distinguen entre religión y espiritualidad, sosteniendo que no son sinónimas pero tampoco contrarias. Afirman que la religión siempre implica espiritualidad, pero la espiritualidad no requiere necesariamente de una religión. Reconocen que en la actual sociedad secularizada urge afinar el análisis y distinguir entre disposición a creer y creencia, entre experiencia religiosa e institución religiosa, entre espiritualidad y religión. Algunos enfatizan que las religiones -como instituciones- están en crisis, entre otras cosas porque quieren imponer una visión particular y autoritaria de la verdad, muchas veces en función de intereses poco claros.

c) La religión es eminentemente cultural y su persistencia es una adaptación evolutiva: Los neurocientíficos afirman que lo religioso ha persistido a partir de su adaptación a distintos contextos y a su capacidad de responder interrogantes que requieren de confianzas básicas $(\mathrm{Fe})$. Señalan que la religión sería un sistema organizado de creencias sostenidas por un grupo étnico, una tribu o una cultura. Los personeros religiosos auto-secularizados coinciden en que la religión ha persistido en el tiempo como un éxito evolutivo y que su desarrollo institucional es una cuestión posterior a la naturalidad del creer. Esta institucionalización de lo religioso sería cultural por excelencia, la que incluye las concepciones de Dios, los dogmas y las particulares creencias.

d) Las religiones pueden ser beneficiosas pero también nocivas:

Hay coincidencia entre los neurocientíficos en que la práctica religiosa/espiritual proporciona a los seres humanos efectos beneficiosos. Las personas que participan en actividades religiosas tienden a enfrentar mejor los problemas emocionales, tienen menos depresión o adicciones y una mejor salud en general. Otros estudios documentan que las personas religiosas encuentran más significado en la vida. Pero también destacan que el excesivo burocratismo del proceso de institucionalización junto con la consolidación de una estructura rígida de doctrinas y dogmas, empobrecen el sentimiento religioso natural.

Los personeros auto-secularizados son más enfáticos al respecto: afirman que las religiones pueden ser "salvíficas" pero también "tóxicas". Cumplen funciones terapéuticas y prosociales pero también pueden funcionar como sistemas opresivos y alienantes. Dependiendo de cómo presenten a Dios, pueden sacar lo mejor de sus fieles: amor, generosidad, compasión, o lo peor: miedo, odio, violencia. Enfatizan

Revista Cultura \& Religión Vol. XIII, 2019 № 2 (julio-diciembre)

Cómo citar este artículo: Dockendorff, C. y Romero, J. (2019). "Neurociencias y auto-secularización del cristianismo: resonancias en iglesias cristianas chilenas”. Revista Cultura \& Religión.13(2). pp. 1-29. 
que las religiones necesitan flexibilidad para comprender que las creencias de hoy pueden cambiar mañana; deben adaptarse para mantener su relevancia en un mundo cambiante.

En relación a ello, expresan que la comprensión de la vida espiritual por parte de las neurociencias, impone un gran desafío a la teología para la definición de elementos centrales de lo religioso, incluido el concepto de Dios. Señalan críticamente que la teología no ha sabido reformular una imagen de Dios acorde con el avance del paradigma científico. Sostienen que en este marco la espiritualidad aparece monopolizada por lo dogmático y lo institucional, y que la creciente crítica a las religiones más las búsquedas espirituales fuera de éstas, demandan la desdogmatización de las religiones.

e) El encuentro entre ciencia y religión:

Los neurocientíficos concuerdan en que desde sus perspectivas resultan inadecuados los conflictos entre ciencia y religión. Reconocen una zona de discordancia pero que ésta queda fuera de sus propuestas de estudiar fenómenos religiosos, en tanto éstos no incluyen doctrinas, dogmas ni los contenidos de las creencias. También coinciden en que se requiere una disciplina que estudie los fenómenos religiosos desde el punto de vista neurocientífico.

Por su parte, los personeros religiosos auto-secularizados apuntan a la superación de la disputa ciencia-religión. A su manera, cada uno de los autores religiosos da por superada la etapa de enfrentamiento entre ciencia y religión y recibe positivamente la incursión de la neurociencia en los fenómenos religiosos. Concuerdan en que la ciencia ya no supone una amenaza contra la religión, si ésta es capaz de renovarse acorde a la mentalidad actual.

A partir de esta convergencia entre las comunicaciones (semánticas, discursos) de los estudios neurocientíficos sobre fenómenos religiosos y las producciones de personeros religiosos identificados como auto-secularizados en la etapa internacional, diseñamos la etapa metodológica en Chile.

\section{Resonancias a comunicaciones auto-secularizadas cristianas en ámbitos eclesiales chilenos}

Dado que no encontramos producciones respecto de estudios neurocientíficos sobre fenómenos religiosos ni su recepción por parte de sectores del cristianismo nacional, el objetivo de esta etapa investigativa consistió en detectar probables resonancias de las comunicaciones (semánticas, discursos) auto-secularizadas estudiadas en el extranjero, al interior de las iglesias cristianas en Chile. Ello pudiese indicar posibles tendencias de cambio

Revista Cultura \& Religión Vol. XIII, 2019 № 2 (julio-diciembre)

Cómo citar este artículo: Dockendorff, C. y Romero, J. (2019). "Neurociencias y auto-secularización del cristianismo: resonancias en iglesias cristianas chilenas". Revista Cultura \& Religión.13(2). pp. 1-29. 
al interior del sistema religioso en el país, como asimismo permitiría observar hasta qué grado de profundidad se vería afectado su acervo de valores propios.

\subsection{El contexto religioso chileno}

En Chile, el contexto religioso se ha modificado paulatinamente en las últimas décadas. Estos cambios se expresan en algunas tendencias generales que se van consolidando. Una primera es la baja progresiva de la adhesión al catolicismo y el lento ascenso del mundo protestante/evangélico. Históricamente, el campo religioso chileno estuvo caracterizado por la alta adhesión al catolicismo; según los Censos superior al $80 \%$ hasta comienzos del 2000. En el Censo de 2012 la cifra baja a un $67 \%$, y según la Encuesta del Centro de Estudios Públicos en 2018 a un 55\%. Para el caso de los evangélicos, la adhesión ha crecido lentamente desde cifras cercanas al 7\% en los Censos de los años 50 y 60 , llegando a un $16 \%$ en el Censo del 2012 y a un $17 \%$ en 2017, según la Encuesta Nacional Bicentenario (2018).

Una segunda tendencia es el crecimiento de quienes se declaran sin religión, ateos o agnósticos. En los Censos de los años 50 y 60 estos grupos estaban por debajo del 4\%, lo que contrasta con el 12\% que informa el Censo del 2012 y con el $38 \%$ en 2018, según la Encuesta Latinobarómetro.

Estas tendencias revelan nuevas formas de vivir las creencias y la pertenencia a las instituciones eclesiales, alentadas por cambios sociales y culturales que tensionan el ámbito religioso. Así por ejemplo, la baja sanción social por no pertenecer a un credo religioso y la mayor libertad en la forma en que las personas establecen su relación con lo religioso, han facilitado el desarrollo de formas personalizadas e individualizadas de vida religiosa. Ejemplo de lo anterior es el denominado "católico a mi manera" (Parker 2005; Ros 2018), estilo de pertenencia a una Iglesia basado en la conveniencia personal, muy marginalizado pero manteniendo la adscripción eclesial. Se observan también formas de participación episódicas en ritos tradicionales como festividades de religiosidad popular y peregrinaciones a santuarios que siguen atrayendo el interés masivo, pero no implican pertenencia y adhesión permanentes. La religión "vivida" se impone a la religión "prescrita" en los procesos socializadores (Mc Guire 2008).

Adicionalmente, se observa una pérdida de credibilidad en las instituciones eclesiales, reforzando con ello el peso cada vez menor del discurso eclesial en el contexto social. La encuesta Latinobarómetro (2017) señala que quienes tienen "mucha" o "algo" de confianza en la Iglesia Católica llegan a un 36\%, mientras en el año 1996 alcanzaban un 80\%. La Encuesta CADEM (2018) señala que la desaprobación alcanza un $76 \%$, posiblemente acelerada por los escándalos sexuales y abusos de poder que han remecido a la Iglesia Católica últimamente en Chile. Además, los debates que ha enfrentado la sociedad chilena

Revista Cultura \& Religión Vol. XIII, 2019 № 2 (julio-diciembre)

Cómo citar este artículo: Dockendorff, C. y Romero, J. (2019). "Neurociencias y auto-secularización del cristianismo: resonancias en iglesias cristianas chilenas”. Revista Cultura \& Religión.13(2). pp. 1-29. 
sobre divorcio, aborto, matrimonio igualitario, han puesto a las Iglesias Católica y Evangélicas entre las instituciones más conservadoras de la sociedad.

Aunque los datos precedentes muestran un escenario marcadamente secularizador, se observa una persistencia en la creencia en Dios, incluso en personas alejadas de las instituciones eclesiales. Según la Encuesta del Centro de Estudios Públicos (CEP), en 2018 ésta llega a un $80 \%$, mientras la creencia en milagros, el cielo y la vida después de la muerte sobrepasa el $65 \%$.

Podemos decir que estamos frente a una población con alta capacidad de elección, que releva la experiencia personal (Bajoit 2003; Olmos 2017), con desconfianza generalizada hacia las instituciones, en una época de postcristiandad (Mardones, 1994). Se suma a esto el desarrollo de una cultura democrática que ensalza la diversidad, por lo que el discurso de las iglesias se vuelve uno más entre muchos otros. Así, el diálogo entre ciencia y religión enfrenta un nuevo contexto, donde las orientaciones de una y otra tienden a ser vistos como equivalentes. Ello obliga al sistema religioso a adecuar sus comunicaciones a las descripciones policontextuales que caracterizan a la sociedad moderna (Luhmann 2007). Dados estos cambios en la realidad chilena, es posible preguntarse por una nueva relación entre religión y ciencia, en el marco del proceso secularizador en marcha y los desafíos que enfrentan las instituciones eclesiales.

\subsection{Metodología etapa resonancias de auto-secularización en iglesias cristianas chilenas}

Utilizamos la metodología cualitativa denominada de muestreo selectivo, de juicio o intencional. Dicha modalidad permite trabajar con números relativamente pequeños de unidades de observación, seleccionadas por sus posibilidades de ofrecer información detallada sobre el asunto de interés para la investigación. El foco fundamental no es la medición sino la comprensión de los fenómenos en toda su complejidad. Martínez-Salgado (2012) propone designar a los entrevistados como "invitados a participar" para subrayar que

en esta forma de trabajo la aceptación de los informantes es un elemento conceptualmente imprescindible y éticamente intrínseco.

Invitamos a participar a laicos/as y teólogos/as sacerdotes, pastores/as y otros/as personeros religiosos chilenos con algún cargo o rol formativo y/o de liderazgo al interior de sus respectivas iglesias. Dado que muchos de los posibles entrevistados pudiesen no conocer el tipo de producciones como las estudiadas en la etapa internacional, confeccionamos un texto de síntesis respecto del cual se les pidieron sus opiniones (herramienta de irritación). Previamente realizamos entrevistas semi-estructuradas a algunos personeros religiosos contactados mediante redes personales/bola de nieve para evaluar la claridad del texto de

Revista Cultura \& Religión Vol. XIII, 2019 № 2 (julio-diciembre)

Cómo citar este artículo: Dockendorff, C. y Romero, J. (2019). "Neurociencias y auto-secularización del cristianismo: resonancias en iglesias cristianas chilenas”. Revista Cultura \& Religión.13(2). pp. 1-29. 
síntesis. Elaboramos un cuestionario de preguntas semi-estructuradas que ofreciese la máxima flexibilidad para recoger las elaboraciones de cada entrevistado/a.

Enviamos un correo electrónico presentando la investigación, adjuntando el texto de síntesis y el cuestionario de preguntas que invitaba a comentar los temas de la síntesis (autoadministrado). Pusimos énfasis en aquellas expresiones auto-secularizadas que pudiesen ser percibidas como complejas o controversiales. El correo electrónico fue enviado a los personeros religiosos registrados en la Guía Eclesiástica de Chile, guía oficial de la Iglesia Católica que incluye a todos los sacerdotes y laicos con responsabilidades a nivel de diócesis y parroquias del país (cerca de 800). El mismo correo electrónico se envió a la base de datos del Centro Ecuménico Diego de Medellín, que cuenta con información de la mayoría de las Iglesias Protestantes presentes en Chile (cerca de 300). Las respuestas recibidas constituirían una muestra de carácter más bien voluntario que intencional, y por supuesto no representativo.

Trabajamos en base a los 25 cuestionarios recibidos, pertenecientes a personeros religiosos, hombres y mujeres, laicos y consagrados. Específicamente, la muestra quedó conformada por 18 católicos: tres sacerdotes, seis teólogos, cinco laicos con cargo actual o reciente en organizaciones religiosas, dos teólogas laicas, y dos laicas con cargos en organizaciones religiosas; y 7 protestantes/evangélicos: un pastor, dos pastoras, dos teólogos laicos, un laico con cargo en una organización religiosa y una teóloga laica. El conjunto de la muestra coincide, en términos generales, con la conformación de la adhesión religiosa a nivel nacional, es decir, aproximadamente un $60 \%$ de católicos y un $20 \%$ de protestantes evangélicos.

Una vez recibidos los cuestionarios, analizamos por separado y en conjunto todas las respuestas a las preguntas mediante análisis iterativo de los contenidos elicitados, vale decir, recurrente y repetidamente hasta reconstruir un orden del contenido con énfasis comprensivo. Se hizo emerger un nuevo orden de la información, que aportó a la simplificación del conjunto de los datos y a la profundización de los contenidos.

Para confeccionar las preguntas del cuestionario utilizado en la etapa investigativa en Chile, sintetizamos expresiones de los autores cristianos (la mayoría teólogos o sacerdotes con formación científica) estudiados en la etapa internacional, como un horizonte indicativo de auto-secularización. No hablamos estrictamente de indicadores sino más bien de expresiones de auto-secularización en tanto pueden utilizar semánticas diferentes:

1. Existe una diferencia entre religión y religiosidad, espiritualidad y experiencia religiosa.

2. La religiosidad es "natural"; la religión es cultural.

3. Las religiones pueden ser beneficiosas, pero también nocivas. 
4. Se hace necesaria una des-dogmatización de las religiones.

5. La experiencia religiosa es más importante que la doctrina, la teología y la normatividad religiosas.

6. La espiritualidad (no así la religión) puede vivirse sin concepto/imagen de Dios.

7. La crisis actual del cristianismo se explica entre otras razones por la mantención de una imagen de Dios alienante, postulada por una Teología dogmática.

8. La ciencia legítimamente puede estudiar fenómenos religiosos.

9. Es posible e importante visualizar una convergencia explicativa entre ciencia y religión.

Las preguntas del cuestionario llevaban un encabezado basado en expresiones de los autores estudiados -controversiales para el pensamiento cristiano tradicional-, como las siguientes:

A. Respecto del origen de la religión:

La religión es un producto mental y su persistencia en el tiempo lleva a definirla como algo más natural que sobrenatural.

¿Cuánto perdería (y/o ganaría) su Iglesia si aceptara que su origen no es sobrenatural?

B. Respecto del concepto o la imagen de Dios:

En Occidente, la crisis actual de las religiones establecidas se da por motivos muy diversos, pero esencialmente por haber presentado una imagen alienante y opresora de Dios.

¿En su Iglesia, quiénes estarían difundiendo una imagen alienante y opresora de Dios?

¿Consideraría como alienante y opresora la imagen de Dios Padre?

¿Estaría usted de acuerdo con la necesidad de reformular la imagen de Dios?

El proceso secularizador de la modernidad ha puesto en entredicho imágenes infantilizadoras de Dios, pero hoy se acepta la expresión de Einstein cuando señala que cree en un Dios que se revela a sí mismo en la armonía de todo lo que existe, no en un Dios que se preocupa por los destinos y acciones de los seres humanos. ¿Le parece a usted que una concepción impersonal (cósmica, inmanentista) de Dios pone en entredicho al Dios personal cristiano?

La teología no ha sabido reformular una imagen de Dios acorde con el avance del paradigma científico. ¿Qué teologías no han sabido reformular la imagen de Dios y cuáles lo han intentado?

C. Sobre los dogmas:

En Europa hace tiempo que se vive la sensación de un proceso de des-dogmatización de la creencia, pero en las iglesias la espiritualidad todavía aparece monopolizada por lo dogmático y lo institucional.

Revista Cultura \& Religión Vol. XIII, 2019 № 2 (julio-diciembre)

Cómo citar este artículo: Dockendorff, C. y Romero, J. (2019). "Neurociencias y auto-secularización del cristianismo: resonancias en iglesias cristianas chilenas”. Revista Cultura \& Religión.13(2). pp. 1-29. 
¿Qué implicancias tendría para su Iglesia aceptar actualmente una des-dogmatización de las creencias?

¿Favorecería usted una desdogmatización de los ritos, la liturgia o el culto y la enseñanza de la doctrina?

D. Sobre la institucionalidad eclesial y el futuro del cristianismo:

El cristianismo es religión, pero podría convertirse solamente en una fe, es decir, una confianza básica en la vida. Sería una fe que es compatible tanto con la religión como con la no religión. ¿Comparte esta visión como futuro posible para el cristianismo? ¿Cómo se imagina el futuro de su religión?, ¿y de su iglesia?

E. Sobre la hipótesis de investigación:

Expusimos a los entrevistados a nuestra hipótesis investigativa: Las producciones neurocientíficas son observadas en contextos cristianos abiertos a este tipo de comunicaciones como un "aval científico", esto es, un nuevo fundamento racional para las religiones que otorgaría mayor validez, credibilidad y legitimidad a la religiosidad en el siglo XXI. ¿Qué le ha parecido en general nuestra hipótesis? ¿Y en particular, qué opina de que la religión necesite o se beneficie con un "nuevo fundamento racional" como aval científico para la religiosidad en esta época secularizada?

\subsection{Tipología: Grados de resonancia a las expresiones auto-secularizadas.}

A partir del análisis de las respuestas al cuestionario, construimos categorías de respuestas estableciendo grados de aceptación/rechazo ante las producciones estudiadas. En base al análisis iterativo del corpus de respuestas, agrupamos a los entrevistados en cuatro grados de resonancia según su apertura a aceptar las principales expresiones de autosecularización.

- Resonancia grado 1. Refleja la mayor apertura a las expresiones de autosecularización consideradas. Valora el discurso de las ciencias y subordina la religión a la vivencia de la religiosidad/espiritualidad. Asimismo, acepta que la religión sea más natural que sobrenatural; la necesaria des-dogmatización de las creencias y una reformulación de la imagen de Dios. Apoya el desarrollo de otras teologías como las teologías contextuales. Los entrevistados clasificados en este tipo de resonancia también se muestran favorables a concebir al cristianismo como una fe, es decir, una confianza básica en la vida, compatible tanto con la religión como con la no religión. Pese a que los entrevistados agrupados en este grado de resonancia muestran la mayor apertura, conservan cierta distancia de la hipótesis de que se requiera un aval científico para las religiones en base a los hallazgos de las investigaciones de la neurociencia.

Revista Cultura \& Religión Vol. XIII, 2019 № 2 (julio-diciembre)

Cómo citar este artículo: Dockendorff, C. y Romero, J. (2019). "Neurociencias y auto-secularización del cristianismo: resonancias en iglesias cristianas chilenas”. Revista Cultura \& Religión.13(2). pp. 1-29. 
- Resonancia grado 2. Muestran una amplia apertura a los temas consultados, en particular a la des-dogmatización de las creencias, los ritos, la liturgia y la doctrina. Al resto de las expresiones de auto-secularización parecen menos abiertos que el grado 1 de resonancia. Entre los temas en que observamos menor apertura está considerar que la religión sea un producto mental y que por lo tanto tenga más bien un origen natural que sobrenatural.

- Resonancia grado 3: Muestra menor apertura a la mayoría de las expresiones indicativas de auto-secularización. Los entrevistados no comparten que las iglesias propicien una imagen alienante de Dios, ni que deba cuestionarse al Dios personal cristiano con una imagen impersonal o cósmica de Dios. Tampoco valoran el aporte de teologías no oficiales, que alientan procesos de des-dogmatización, aunque sí aceptan aquellas que han sabido reformular la imagen de Dios. Rechazan la hipótesis de que la religión necesite un aval científico proveniente de los hallazgos de las neurociencias.

- Resonancia grado 4. Muestra la menor apertura al conjunto de los temas consultados, exhibiendo un alto grado de rechazo. Los entrevistados rechazan que el cristianismo pueda convertirse solo en una fe, sin una religión. Son cerrados a la necesidad de reformular la imagen de Dios y a favorecer procesos de des-dogmatización, por lo que critican las teologías que alientan estas posibilidades. También se muestran reticentes a cuestionar la institucionalidad eclesial, justificando la necesidad de su estructura y poder.

\subsection{Resultados: Distribución de Grados de Resonancia por entrevistados, Iglesias, género y tramo etario. ${ }^{2}$}

Una primera constatación general, es que no observamos tipos puros que muestren ya sea total aceptación o total rechazo a las expresiones de auto-secularización consultadas. Todos los entrevistados muestran apertura hacia algunas expresiones como también grados diferenciales de rechazo. En cuanto a la conformación de la muestra, los grados de resonancia 1 y 2 suman 18 entrevistados mientras los grados 3 y 4 totalizan 7 . El grado 2 es el que concentra el mayor número de entrevistados (52\%), acogiendo en su interior un amplio espectro en cuanto a género, edad y pertenencia eclesial. Los grados 1 y 4 representan un $20 \%$ cada uno. Finalmente, el grado 3 agrupa solo al $8 \%$ de los consultados. (Ver Tabla 1)

\footnotetext{
${ }^{2}$ Los números y porcentajes sólo refieren a la muestra de 25 casos y no son representativos de la distribución a niveles más amplios
}

Revista Cultura \& Religión Vol. XIII, 2019 № 2 (julio-diciembre)

Cómo citar este artículo: Dockendorff, C. y Romero, J. (2019). "Neurociencias y auto-secularización del cristianismo: resonancias en iglesias cristianas chilenas”. Revista Cultura \& Religión.13(2). pp. 1-29. 
Tabla 1

Distribución de entrevistados según Grados de Resonancia

\begin{tabular}{lll}
\hline Grado & $\mathrm{N}^{\circ}$ de entrevistados & Porcentaje \\
\hline Grado 1 de resonancia & 5 & $20 \%$ \\
\hline Grado 2 de resonancia & 13 & $52 \%$ \\
\hline Grado 3 de resonancia & 2 & $8 \%$ \\
\hline Grado 4 de resonancia & 5 & $20 \%$ \\
\hline Total & 25 & $100,0 \%$ \\
\hline
\end{tabular}

Fuente: Elaboración propia.

\section{Resultados según adhesión/pertenencia eclesial:}

Desde la adscripción religiosa, vemos que la submuestra de católicos abarca los cuatro grados de resonancia. Se agrupan fundamentalmente en el grado $2(44,5 \%)$ y 4 $(27,8 \%)$. Cabe destacar que el grado 4 (la menor aceptación de expresiones autosecularizadas) es el que contiene la mayor presencia de personal consagrado de la Iglesia Católica. Por su parte, en la submuestra de evangélicos/protestantes la resonancia grado 2 representa el 71,4\%. Las resonancias grado 1 y 3 representan un 14,3\% cada una, sin presencia de resonancias del grado 4. (Ver Tabla 2)

\section{Tabla 2}

Resultados según iglesias

\begin{tabular}{lcc}
\hline & Católicos (72,0\%) & $\begin{array}{c}\text { Evangélicos/protestantes } \\
(28,0 \%)\end{array}$ \\
\hline Grado 1 & $22,1 \%$ & $14,3 \%$ \\
\hline Grado 2 & $44,5 \%$ & $71,4 \%$ \\
\hline Grado 3 & $5,6 \%$ & $14,3 \%$ \\
\hline Grado 4 & $27,8 \%$ & $0 \%$ \\
\hline Total & $100,0 \%$ & $100,0 \%$ \\
\hline Fuente: Elaboración propia. &
\end{tabular}

Quienes adhieren al catolicismo aparecen algo más conservadores al ubicarse en un $33,4 \%$ en los grados 3 y 4, mientras solo el 14,3\% de los evangélico/protestante clasifican en esos grados de resonancia. Ello reflejaría una mayor apertura a la auto-secularización por parte de los evangélicos/protestantes, lo que se vería confirmado con su falta de presencia en el grado de resonancia 4, el más conservador.

Revista Cultura \& Religión Vol. XIII, 2019 № 2 (julio-diciembre)

Cómo citar este artículo: Dockendorff, C. y Romero, J. (2019). "Neurociencias y auto-secularización del cristianismo: resonancias en iglesias cristianas chilenas”. Revista Cultura \& Religión.13(2). pp. 1-29. 


\section{Resultados según género}

La muestra de entrevistados se divide en un $72 \%$ de hombres y un $28 \%$ de mujeres. En el siguiente cuadro se observa su distribución por grado de resonancia (Ver Tabla 3):

\section{Tabla 3}

Resultados según género

\begin{tabular}{lll}
\hline Grado & Mujeres (28,0\%) & Hombres $\mathbf{( 7 2 , 0 \% )}$ \\
\hline Grado 1 & $28,7 \%$ & $16,6 \%$ \\
\hline Grado 2 & $57,1 \%$ & $50,0 \%$ \\
\hline Grado 3 & $0 \%$ & $11,2 \%$ \\
\hline Grado 4 & $14,2 \%$ & $22,2 \%$ \\
\hline Total & $100,0 \%$ & $100,0 \%$ \\
\hline
\end{tabular}

Fuente: Elaboración propia.

Como se observa, las mujeres muestran una mayor apertura a las comunicaciones auto-secularizadas al alcanzar un $85,8 \%$ de ubicación en los grados 1 y 2 de resonancia. También exhiben ausencia del grado 3 de resonancia y un menor porcentaje que los hombres de grado 4. La submuestra de hombres muestra menos resonancias grado 1 y $2(66,6 \%)$ y mayor presencia de los grados de resonancia 3 y $4(33,4 \%)$ lo que para el caso de la submuestra de mujeres es solo de un $14,2 \%$.

\section{Resonancias según tramos etarios:}

La muestra fue dividida en tres grupos etarios: menores de 50 años; entre 50 a 65 años y mayores de 65 años (Ver Tabla 4). Su distribución según grados de resonancia es la siguiente:

Tabla 4

Resonancias según tramos etarios

\begin{tabular}{lccc}
\hline Grado & $\begin{array}{c}\text { Menores de 50 } \\
\text { años (20\%) }\end{array}$ & $\begin{array}{c}\text { Entre 50 y 65 } \\
\text { años (48\%) }\end{array}$ & $\begin{array}{c}\text { Mayores de 65 } \\
\text { años (32\%) }\end{array}$ \\
\hline Grado 1 & $20,0 \%$ & $16,7 \%$ & $28,6 \%$ \\
\hline Grado 2 & $40,0 \%$ & $66,7 \%$ & $42,8 \%$ \\
\hline Grado 3 & $20,0 \%$ & $8,3 \%$ & $0 \%$ \\
\hline Grado 4 & $20,0 \%$ & $8,3 \%$ & $28,6 \%$ \\
Total & $100,0 \%$ & $100,0 \%$ & $100,0 \%$ \\
\hline
\end{tabular}

Fuente: Elaboración propia. 
El grado 2 de resonancia concentra el mayor porcentaje en los tres grupos etarios. El tramo etario de 50 a 65 años muestra la mayor presencia en el grado 2 y, aunque entre los menores de 50 el grado 2 representa el doble de cada uno de los otros tres grados, a la vez es el más bajo en comparación con los otros grupos etarios. El grupo entre 50 y 65 años aparece como el más abierto, seguido de los mayores de 65 años y en último lugar los menores de 50. Los mayores de 65 años se distribuyen polarizadamente entre los Grados 1 y 4.

En cuanto a las resonancias más conservadoras (grados 3 y 4) observamos una significativa menor presencia en el grupo etario de 50 a 65 años $(16,6 \%)$ mientras los menores de 50 totalizan un $40 \%$ y los mayores de 65 un $28,6 \%$.

No obstante se trata de una muestra no representativa, resulta indicativo del panorama eclesial cristiano chileno, que de los 3 sacerdotes católicos, 2 estén en el grado 4 y sólo uno en el grado 2 de resonancia. La única religiosa consagrada y teóloga católica también está en el grado 4. Por otra parte, de los 6 teólogos laicos católicos, 5 están en los grados 1 y 2, y sólo uno en el grado 4 (con cargo en la jerarquía eclesiástica). La única teóloga laica católica aparece en el grado 1, mientras que de las dos laicas católicas con cargos en organizaciones religiosas una se ubica en el grado $1 \mathrm{y}$ la otra en el grado 2. Por su parte, tanto el pastor como las dos pastoras protestantes se ubican en los grados 1 y 2 , mientras que de los 4 laicos protestantes 3 se ubican en el grado 2, solo uno en el grado 3 y ninguno en el grado 4 . En general, se aprecia así una mayor apertura por parte de los laicos, los evangélicos/protestantes y las mujeres, mientras el personal consagrado, los católicos y los hombres concentran las expresiones más conservadoras. (Ver anexo 1)

Nuestra investigación no se enfocó en qué contextos (y sub-contextos) eclesiales cristianos se muestran más abiertos o cercanos a las propuestas auto-secularizadas, sino en la resonancia en Chile -positiva o negativa- a los contenidos (las semánticas, discursos) controversiales que surgen de los procesos de auto-secularización extranjeros. Sostenemos que éstas encarnan los desafíos más profundos al sistema religioso en la sociedad contemporánea. Así, dicha resonancia en Chile podría indicar tendencias respecto del futuro del cristianismo en el país.

\section{Resultados diferenciales ante expresiones auto-secularizadas}

Para la muestra en general, el conocimiento acerca de los estudios neurocientíficos sobre fenómenos religiosos es bajo, según la auto-calificación de los entrevistados. Les preguntamos "Antes de recibir nuestro resumen, ¿tenía usted conocimiento de que las neurociencias estaban estudiando la experiencia religiosa? ¿Cómo evaluaría su conocimiento? (Elija una de las alternativas y comente brevemente)"; los resultados se muestran en la Tabla 5:

Revista Cultura \& Religión Vol. XIII, 2019 № 2 (julio-diciembre)

Cómo citar este artículo: Dockendorff, C. y Romero, J. (2019). "Neurociencias y auto-secularización del cristianismo: resonancias en iglesias cristianas chilenas”. Revista Cultura \& Religión.13(2). pp. 1-29. 


\section{Tabla 5}

Nivel de conocimiento sobre estudios neurocientíficos acerca de fenómenos religiosos

\begin{tabular}{lcc}
\hline Nivel de conocimiento & Número de entrevistados & Porcentaje \\
\hline Mucho conocimiento & 2 & $8 \%$ \\
\hline Algún conocimiento & 7 & $28 \%$ \\
\hline Poco conocimiento & 12 & $48 \%$ \\
\hline Ningún conocimiento & 4 & $16 \%$ \\
\hline Total & 25 & $100,0 \%$ \\
\hline
\end{tabular}

Fuente: Elaboración propia.

Como se puede observar, el conocimiento declarado acerca de los estudios neurocientíficos sobre fenómenos religiosos es mayoritariamente "Poco", el que sumado a "Ningún conocimiento" representan un 64\%. Ello contrasta con el 8\% que declara tener "Mucho conocimiento".

No obstante, este desconocimiento general, observamos que los entrevistados otorgan mucha relevancia a que las neurociencias indaguen sobre fenómenos religiosos. Les preguntamos:

- ¿Qué le parece este interés de las neurociencias en los fenómenos religiosos?

(Elija una de las alternativas y comente brevemente):

a) ¿Diría que es un tema muy relevante para la religión actualmente?

b) ¿Sería más bien un tema interesante pero no fundamental?

c) ¿O, que es una moda pasajera y no reviste mayor interés?

El alto interés se ve expresado en que una mayoría (68\%) señala que le parece "muy relevante" el interés de las neurociencias en dichos fenómenos (Ver Tabla 6).

\section{Tabla 6}

Grado de relevancia que se otorga a que las neurociencias investiguen fenómenos religiosos

\begin{tabular}{lcc}
\hline Grado de Relevancia & Número de entrevistados & Porcentaje \\
\hline Muy relevante & 17 & $68 \%$ \\
\hline Interesante & 8 & $32 \%$ \\
\hline No reviste interés & 0 & $0 \%$ \\
\hline Total & 25 & $100,0 \%$ \\
\hline Fuente: Elaboración propia & &
\end{tabular}

Fuente: Elaboración propia.

Revista Cultura \& Religión Vol. XIII, 2019 № 2 (julio-diciembre)

Cómo citar este artículo: Dockendorff, C. y Romero, J. (2019). "Neurociencias y auto-secularización del cristianismo: resonancias en iglesias cristianas chilenas”. Revista Cultura \& Religión.13(2). pp. 1-29. 
Junto a la alta valoración de los estudios científicos sobre fenómenos religiosos, las otras expresiones auto-secularizadas con mayor aceptación son: la des-dogmatización de las creencias; una opinión crítica al papel de la institucionalidad de las iglesias; una mirada optimista a los cambios actuales y al futuro de las iglesias cristianas; el desarrollo de nuevas teologías y el tema de la reformulación de la imagen de Dios, que registra diversos matices.

\title{
Expresiones sobre la relevancia otorgada a los estudios de las neurociencias:
}

\begin{abstract}
Yo creo que es súper relevante porque realmente le permite a la experiencia religiosa tener un fundamento para poder dialogar con otras ciencias y con el conocimiento en la sociedad actual, que es una sociedad extremadamente crítica. Eso sí que requiere una teología o un pensar creyente que sea capaz de cuestionarse radicalmente... Para mí es muy desafiante como teólogo también, porque te permite tener un vínculo con la sociedad actual en su camino de emancipación, de superación de creencias que le han hecho tanto mal a las personas y también a la naturaleza. (Entrevistado 18, Grado 2 de resonancia)

Para mí es un tema relevante, ya que nos ayuda a discernir el valor de las religiones, de la espiritualidad y de lo sagrado en el cerebro humano. En tiempos de secularización el diálogo de las religiones con otras ciencias nos parece de fundamental importancia, pues nos abre mundos desconocidos para resignificar en lugar de lo religioso en la humanidad. (Entrevistada 10, Grado 2 de Resonancia)

El interés de las neurociencias en los fenómenos religiosos me parece muy justificado, debido a que se toma en serio la estructura del ser humano, sus deseos más profundos en cuanto ser en el mundo y la posibilidad innata de conocer a Dios, sin que sepa, con frecuencia, a qué apunta su "corazón inquieto hasta que descanse en Ti” (San Agustín). (Entrevistada 9, Grado 4 de Resonancia)
\end{abstract}

Junto a la aceptación de la des-dogmatización de las creencias, las siguientes citas expresan una consecuente crítica a la institucionalidad religiosa:

El sistema de creencias sostenido por la Iglesia es avalado por los dogmas, y sin ellos el sistema burocrático y de poder de esta institución se desmorona. Pero la teología bíblica nos enseña que el verdadero poder del reinado de Dios es un poder para servir, y no para ser servido...En el fondo ese es el único poder que Dios le ha concedido a la Iglesia, ser una comunidad de fe que por amor se hace servidora de todos y todas. (Entrevistado 11, Grado 2 de resonancia)

El creyente común, e incluso el docto, necesitan tener certidumbre, que es lo que dan los dogmas... El paquete actual de dogmas de la Iglesia Católica se fue armando a través de la historia en gran parte para superar disputas teológicas mediante decisiones conciliares. Se le daba máxima importancia a la "verdad" y en base a ella se construía la ortodoxia. Hoy, que somos cada vez más conscientes de que nuestro pensamiento humano es siempre relativo a nuestra condición humana y que hablar de la "verdad" en un sentido esencialista es pretencioso, quizás ha llegado el momento en que la fe compartida apunte más a la ortopraxis que a la ortodoxia. (Entrevistado 2, Grado 2 de resonancia)

No obstante, entrevistados agrupados en el Grado 4 de resonancia no se muestran abiertos a la des-dogmatización de las creencias. Defienden la vigencia de los dogmas como intransable, aludiendo a su origen divino, por ende, no sujeta a los avatares de la historia.

Revista Cultura \& Religión Vol. XIII, 2019 № 2 (julio-diciembre)

Cómo citar este artículo: Dockendorff, C. y Romero, J. (2019). "Neurociencias y auto-secularización del cristianismo: resonancias en iglesias cristianas chilenas”. Revista Cultura \& Religión.13(2). pp. 1-29. 
La religión no es un sentimiento, aunque los incluya. Es imprescindible cuestionarse sobre la verdad. Y un dogma no es un sentimiento o una opinión, sino la Verdad Revelada, si esa se pierde, perdemos lo que conocemos sobre la verdad de Dios. (Entrevistado 6, Grado 4 de resonancia)

La visión optimista sobre un nuevo futuro para las religiones y/o iglesias es sostenida por los grados de resonancia 1, 2 y 3 en base a valorar los cambios que sufrirán las iglesias, mientras la visión optimista del grado 4 aspira a una renovación de las iglesias que ayudaría a redescubrir sus raíces, aludiendo con ello a elementos más bien tradicionales.

En el futuro las Iglesias van a ser pequeños guetos y la gente va a vivir de otro modo. Lo que siento es justamente la espiritualidad cristiana porque para mí es un símbolo de otro sentido de lo sagrado, digamos, que Dios no sea un poderoso sino que sea un niño pobre y que sea mujer, y enfermo, es dar vuelta nuestro sentido de lo sagrado. (Entrevistada 22, Grado 1 de resonancia)

Creo que en Chile seremos una iglesia más pequeña, con una vida comunitaria más significativa. Además, veo que volveremos con más fuerza a nuestras raíces, lo que dará más sentido a la vida de los cristianos, sus celebraciones y su vida. (Entrevistado 4, Grado 4 de resonancia)

El futuro de la Iglesia católica es imprevisible, pero siempre basado en la fidelidad y confianza en Jesucristo, quien nunca abandona a Su Iglesia, siendo El mismo Su Cabeza. (Entrevistada 9, Grado 4 de resonancia)

Una temática que concita cierta apertura son las nuevas teologías, en particular la necesidad de que la reflexión teológica sea coherente con los cambios culturales actuales.

Las teologías más tradicionales o conservadoras (de tradición católica y evangélica) suelen hablar de Dios como Padre omnipotente todopoderoso, glorioso etc. (un Dios bastante lejano y emperador masculino), y no han querido reformular esta imagen, porque sirve a los intereses de los varones de poder en nuestro mundo (hasta el mismo pastor). Las teologías políticas y de la liberación, ecológicas, feministas y eco-feministas se han abierto a nuevas imágenes de Dios. (Entrevistada 21, Grado 2 de resonancia)

Expresiones de la amplia aceptación a la reformulación de la imagen de Dios: "El rol del quehacer teológico debería no sólo centrarse en los cambios discursivos de la teología, sino focalizarse constantemente en las imágenes de Dios que surgen." (Entrevistado 3, Grado 3 de resonancia); "Creo que deberíamos hablar de imágenes de Dios. Considerar la diversidad construida a partir de la experiencia de las personas." (Entrevistada 10, Grado 2 de resonancia); "La imagen que nos ha llegado vía patriarcal y machista, ya no resiste análisis." (Entrevistado 7, Grado 1 de resonancia).

Observamos, no obstante, una menor aceptación de imágenes impersonales de Dios (cósmica, inmanentista), y cuando llegan a aceptarse se enfatiza que no ponen en entredicho la imagen del Dios personal cristiano.

Revista Cultura \& Religión Vol. XIII, 2019 Nº 2 (julio-diciembre)

Cómo citar este artículo: Dockendorff, C. y Romero, J. (2019). "Neurociencias y auto-secularización del cristianismo: resonancias en iglesias cristianas chilenas”. Revista Cultura \& Religión.13(2). pp. 1-29. 
No son antagónicos. El Dios energía universal que activa el movimiento perpetuo del universo y de la vida es, sin duda, el Dios de Jesús: la Vida. Y esa Vida es Amor: la energía que mueve todo. Esa energía es Dios Padre, entendiendo 'padre' como fuente de Vida. (Entrevistado 1, Grado 1 de resonancia)

De acuerdo con la teología católica fuimos hechos a imagen y semejanza de Dios. Y la principal semejanza con él es la capacidad de amar. Su mensaje es un mensaje de amor, que nos invita a amarlo a Él, a nosotros mismos y al prójimo. Si lo definimos como una inteligencia cósmica e impersonal le quitamos lo más importante de su mensaje. Sería como el Gran Arquitecto de los Masones. (Entrevistado 23, Grado 3 de resonancia)

Finalmente, la expresión auto-secularizada de que el concepto de Dios tenga un origen natural -producto de funciones cerebrales y procesos culturales-, recibió muy escasa aceptación:

Es cierto que la imagen que el hombre tiene de Dios está influida por su experiencia, su cultura, su historia... Pero esa imagen está siendo constantemente sometida a revisión por la acción de Dios, que interpela al hombre en la historia de formas diversas. Para el cristianismo hay una apertura natural a lo religioso (y esto, al parecer, lo confirma la neurociencia), pero esa capacidad le ha sido dada para el encuentro personal con el Dios personal (Entrevistado 4, grado de resonancia 4)

Por último, la menor aceptación entre todos los temas consultados la encontramos respecto a la hipótesis de que los hallazgos de los estudios neurocientíficos en temas religiosos puedan servir de aval científico para la religión: "Estoy de acuerdo y creo que un grupo reducido de estudiosos e investigadores estaríamos de acuerdo con la afirmación. Pero en general el mundo religioso no lo vería muy bien." (Entrevistado 7, Grado 1 de resonancia);

Para la cultura actual, me parece que podría ser una manera de otorgar mayor validez, credibilidad y legitimidad, ciertamente. Yo como profesora me doy cuenta que podría ser para las nuevas generaciones, no para mí, yo no lo necesito. Creo que la mayor legitimidad la debe dar no solo un fundamento científico sino la práctica, como cuando dice el evangelio: miren cómo se aman los cristianos. No hay que explicar ni decir nada, ahí hay una experiencia, pero ciertamente creo que para las nuevas generaciones que están negando esa experiencia, serviría. (Entrevistada 22, resonancia Grado 1)

Para mí, siendo teóloga, las religiones no necesitan un "aval científico". Aunque me interesa que se esté descubriendo que la espiritualidad es "natural" en los seres humanos, y detectable en procesos cerebrales, creo que la religiosidad tiene otro fin que la ciencia...Para mí las religiones buscan respuestas y formas de enfrentar las grandes preguntas de la existencia humana en comunidad: preguntas por el sentido, los límites de nuestro poder, mejores maneras de convivir y de llegar a nuestra dignidad plena en sociedad...Estas preguntas no necesitan aval científico para tener el derecho de existir. (Entrevistada 21, Grado 2 de resonancia)

Revista Cultura \& Religión Vol. XIII, 2019 № 2 (julio-diciembre)

Cómo citar este artículo: Dockendorff, C. y Romero, J. (2019). "Neurociencias y auto-secularización del cristianismo: resonancias en iglesias cristianas chilenas”. Revista Cultura \& Religión.13(2). pp. 1-29. 


\section{Conclusiones}

La idea de investigar las producciones neurocientíficas sobre fenómenos religiosos y su resonancia en sectores del cristianismo, surge de vislumbrar que por primera vez en la sociedad moderna, al conocimiento que continuamente aporta la ciencia sobre el mundo natural podría agregarse ahora un fundamento científico a mucho de lo que aún se mantiene en terreno religioso.

Hasta antes de estas investigaciones neurocientíficas no había aparecido la ciencia como potencial aliada de la religión, no ya para deconstruir creencias sino para ayudar a fundamentar sus propuestas de valorar y cultivar la religiosidad. Por primera vez este tratamiento de fenómenos religiosos que desborda el ámbito de las religiones institucionalizadas y pasa a ser de interés científico, podría impactar positivamente en el sistema religioso, llegando a reforzar los procesos de auto-secularización emergentes.

El aporte de la presente investigación destaca que los resultados de tales investigaciones neurocientíficas han impactado y están teniendo resonancia positiva en sectores del cristianismo, principalmente en Europa y Norteamérica, reforzando dichos procesos de auto-secularización. Ante tal panorama, ¿cómo se aprecia esta situación en Chile? Una primera reflexión es que si bien nuestros entrevistados concuerdan con varias de las expresiones indicativas de auto-secularización con las que fueron interpelados, el nivel de radicalidad de sus respuestas es menor que aquel de los contextos extranjeros (Europa y Norteamérica). Apertura, sí, ciertamente, pero no como para afirmar que estamos ante un avanzado proceso de auto-secularización.

Como se mencionara anteriormente, el $72 \%$ de los cuestionarios recibidos se ubicó en los grados de mayor resonancia (grados 1 y 2), indicando una alta resonancia a las expresiones auto-secularizadas. Sin embargo, las respuestas -como veremos- no coinciden plenamente con tal apreciación. Del conjunto de las expresiones auto-secularizadas destaca con amplia resonancia positiva la forma en que se comprende por un lado la religión (institucionalizada) y por otro la religiosidad (espiritualidad, experiencia religiosa). El concepto de religiosidad implica que lo religioso pueda vivirse fuera de las estructuras eclesiales, valorando la experiencia religiosa por sobre el dominio de lo doctrinal, lo dogmático y las prescripciones rituales oficiales. Esta positiva resonancia a que lo central de lo religioso sea una vivencia personal, recogida en los conceptos de religiosidad, espiritualidad, experiencia religiosa, se proyecta como la base necesaria para la viabilidad futura de las iglesias. Ello conlleva una crítica a la teología oficial por centrarse en la defensa del dogma, la doctrina y la tradición como el fundamento de la fe, y de paso a la estructura jerárquica y al abuso de poder por parte de estas instituciones. La crítica a imágenes alienantes y opresivas de Dios atribuidas a dichas estructuras eclesiales, conduce a la 
valoración de contenidos que enfatizan lo femenino, lo ecológico, concepciones del cosmos y la energía ligados a la divinidad que aportan las teologías emergentes distintas de la oficial.

Destacamos, por último, que a pesar de las críticas encontramos una positiva visión acerca del futuro de las iglesias y de la religión. Esta visión se construye sobre la idea de que surgirán estructuras de menor tamaño, centradas en la espiritualidad compartida. El futuro del cristianismo, aunque es visto como en creciente reducción numérica, se considera en un proceso ascendente hacia lo experiencial y la vida comunitaria. No obstante, se observa muy poca apertura a la idea de que el cristianismo se convierta solamente en una fe, entendida como una confianza básica en la vida, compatible tanto con la religión como con la no religión. Esto implica que en última instancia se valora la existencia de las iglesias (religión institucionalizada), necesarias para el componente de la vida comunitaria.

Nuestro hallazgo central se relaciona con la afirmación de que no obstante la amplia apertura en Chile a las expresiones auto-secularizadas, no se alcanza el nivel de radicalidad manifestada en las producciones extranjeras estudiadas (Europa y Norteamérica). Ello se observa principalmente en torno a dos temáticas que exhiben aparentes contradicciones:

1. La existencia incuestionable de Dios. Aun cuando critican visiones alienantes o infantilizadoras y aceptan la resignificación del concepto/imagen de Dios, su "ser" no se pone en duda. Admiten que la religión tenga un origen natural, producto de funciones cerebrales y procesos culturales, pero no así que Dios pueda tener ese mismo origen.

2. La innecesariedad de que los hallazgos de las ciencias puedan servir de aval científico para la religiosidad del siglo XXI (nuestra hipótesis). Ello contrasta con la relevancia que otorgan a que las neurociencias indaguen sobre fenómenos religiosos.Con respecto al rechazo a aceptar que el concepto de Dios tenga un origen natural producto de funciones cerebrales y procesos culturales-, las expresiones de los entrevistados son elocuentes. Si bien la neurociencia confirma una tendencia humana natural hacia lo religioso, ésta le es dada por Dios, para el encuentro personal con él ${ }^{3}$. Esta aparente contradicción se comprende desde la teoría de los acervos de valores propios: las imágenes de Dios han sufrido reiterados cuestionamientos en la historia teológica y modificada valores propios a grados menores de condensación, pero jamás han llegado a cuestionar su origen, excepto en los casos de gran autosecularización no presentes en Chile. Dios puede diversificar sus imágenes, pero sin lugar a duda "Es". El valor propio de la existencia indudable de Dios es tal vez el valor propio más profundamente condensado y probablemente el más difícil de cambiar en el proceso de auto-secularización.

\footnotetext{
${ }^{3}$ Ver entrevistado 4.
}

Revista Cultura \& Religión Vol. XIII, 2019 Nº 2 (julio-diciembre)

Cómo citar este artículo: Dockendorff, C. y Romero, J. (2019). "Neurociencias y auto-secularización del cristianismo: resonancias en iglesias cristianas chilenas”. Revista Cultura \& Religión.13(2). pp. 1-29. 
Respecto de lo anterior podemos decir que, a diferencia de las expresiones de los personeros religiosos extranjeros estudiados -la mayoría sacerdotes, pero a la vez científicos, la totalidad de los entrevistados chilenos respondió desde su pertenencia a una iglesia y su calidad de personas de fe. No respondieron observando desde la sociedad la crisis de las iglesias cristianas respecto a la pérdida de fieles (y vocaciones) como resultado del predominio de la razón secular moderna. Esta perspectiva no parece prioritaria para quienes están viviendo en un ámbito religioso cuya crisis es la que sufre la institucionalidad de sus propias iglesias, fundamentalmente en el ámbito del poder y sus abusos.

En consecuencia, a diferencia de los personeros religiosos extranjeros, los entrevistados chilenos no ponen en primer plano el progresivo rechazo a lo religioso de las nuevas generaciones, lo que podría constituir el mayor desafío para el cristianismo (descontando las crisis institucionales). Las nuevas generaciones, socializadas acorde a la racionalidad moderna, sin fe o con escasa educación religiosa, no logran acceder a la vivencia espiritual o desarrollar una espiritualidad. Es a la percepción de esa crisis que el sistema religioso reacciona con procesos auto-reflexivos que han redundado en una progresiva autosecularización. Y ésta se expresa en el intento por responder a las exigencias cognitivas venidas principalmente del sistema de la ciencia en la sociedad contemporánea, aceptando y utilizando verdades científicas y en consecuencia abandonando lo dogmático-doctrinario.

En cuanto a la innecesariedad de que los hallazgos de las ciencias puedan servir de aval científico para la religiosidad del siglo XXI, junto a la relevancia que otorgan los entrevistados chilenos a los estudios neurocientíficos, ¿cómo justifican dicha relevancia? Entre sus expresiones indicativas de este alto interés en los estudios científicos sobre fenómenos religiosos aparecen fundamentaciones que apuntan -al igual que nuestra hipótesis- a la legitimación de la experiencia religiosa en la sociedad actual. Las aproximaciones científicas a los fenómenos religiosos son relevadas como fundamentales para la comprensión y orientación de la vivencia religiosa. Incluso en el grado de resonancia más conservador, encontramos que el interés de las neurociencias por los fenómenos religiosos resulta "muy justificado"4

Sin embargo, observamos que por sobre esta alta valoración priman las expresiones que nos han hecho concluir que, en general, una de las menores aperturas se da respecto del potencial aval científico como un nuevo fundamento racional para la religiosidad. La expresión general es que resulta innecesario ${ }^{5}$. Detrás de ello podemos vislumbrar otro valor propio religioso profundamente arraigado (de gran condensación): la superioridad incuestionable de la verdad revelada por sobre cualquier otra fuente de conocimiento.

\footnotetext{
${ }^{4}$ Ver entrevistada 9.

${ }^{5}$ Ver citas en resultados (pág. 20)
}

Revista Cultura \& Religión Vol. XIII, 2019 Nº 2 (julio-diciembre)

Cómo citar este artículo: Dockendorff, C. y Romero, J. (2019). "Neurociencias y auto-secularización del cristianismo: resonancias en iglesias cristianas chilenas”. Revista Cultura \& Religión.13(2). pp. 1-29. 
Resumiendo, encontramos apertura e interés en conocer lo que las neurociencias investigan sobre lo religioso, pero la idea que prevalece es que la ciencia solo puede acceder a constataciones de los efectos de la religión, pero no explica cuestiones religiosas que no son posibles de comprender por la racionalidad científica. La forma aceptada de relación entre ciencia y religión es el diálogo, afirmando que la religión se sustenta por sí misma, no requiere de explicaciones científicas. Las expresiones sobre la pertinencia de un diálogo entre ciencia y religión junto con manifestaciones de la innecesariedad de que los hallazgos de las ciencias sirvan de aval científico para la religiosidad del siglo XXI, podrían considerarse indicativas de que la brecha insalvable entre religión y ciencia aún se mantiene en el cristianismo chileno.

Por su parte, la auto-secularización apunta a la posibilidad de una mayor convergencia explicativa entre ciencia y religión. En comparación con las comunicaciones de los personeros religiosos/científicos extranjeros estudiados, los entrevistados(as) en Chile, a pesar de que muestran una alta resonancia a las expresiones auto-secularizadas, ésta no logra los niveles de apertura que alcanzan los primeros. En Chile, la menor aceptación de verdades científicas y la consiguiente persistencia de aquellas fundadas en la revelación, refleja una menor resonancia a las irritaciones venidas principalmente del sistema de la ciencia. Podríamos concluir que en Chile predominaría la disposición a un diálogo fructífero, pero persistiría una idea implícita de inconmensurabilidad entre ciencia y religión.

\section{Referencias}

Ashbrook, J. (1984). "Neurotheology: The Working Brain and the Work of Theology". Zygon. Journal of Religion and Science 19: 331- 350. https://doi.org/10.1111/j.14679744.1984.tb00934.x

Austin, J. (1999). Selfless Insight: Zen and the Meditative Transformations of Consciousness. Cambridge: MIT Press.

Austin, J. (2011). Meditating Selflessly: Practical Neural Zen. Cambridge: MIT Press.

Austin, J. (2014). Zen Brain Horizons: Toward a Living Zen. Cambridge: MIT Press.

Bajoit, G. (2003). Todo cambia. Análisis sociológico del cambio social y cultural en la sociedad contemporánea. Santiago de Chile: LOM Editores.

Brown, W. (2009). Neuroscience, Psychology, and Religion: Illusions, Delusions, and Realities of Human Nature. USA: Templeton Foundation Press.

Brown, W. y Strawn, B. (2012). The Physical Nature of Christian Life: Neuroscience, Psychology and the Church. Cambridge: Cambridge University Press.

Burity, J. (2008). "Religión, Política y Cultura". Tempo social 20 (2): 83-113. http://dx.doi.org/10.1590/S0103-20702008000200005.

CADEM. (2018). Encuesta Plaza Pública, Estudio Número 238. https://plazapublica.cl/encuestas/plaza-publica-cadem-estudio-n-238/

Revista Cultura \& Religión Vol. XIII, 2019 № 2 (julio-diciembre)

Cómo citar este artículo: Dockendorff, C. y Romero, J. (2019). "Neurociencias y auto-secularización del cristianismo: resonancias en iglesias cristianas chilenas”. Revista Cultura \& Religión.13(2). pp. 1-29. 
Centro de Estudios Públicos (CEP). (2018). Estudio nacional de opinión pública, octubrenoviembre 2018 https://www.cepchile.cl/cep/site/artic/20181218/asocfile/20181218093906/encuesta cep_oct_nov2018_te_religion.pdf

Creswell, J. (2009). Research Design, Qualitative, Quantitative and Mixed Methods Approaches. London: SAGE.

Davidson, R., Kabat-Zinn, J., Schumacher, J., Rosenkranz, M., Muller, D., Santorelli, S., Urbanowski, F., Harrington, A., Bonus, K., Sheridan, J. (2003). “Alterations in Brain and Immune Function Produced by Mindfulness Meditation". Psychosomatic Medicine 65 (4): 564-570. https://www.ncbi.nlm.nih.gov/pubmed/12883106

Davidson, R., Lutz, A. (2008). "Buddha's Brain: Neuroplasticity and Meditation [In the Spotlight]". IEEE Signal Processing Magazine 25 (1): 176-174. https://www.ncbi.nlm.nih.gov/pmc/articles/PMC2944261/

Dockendorff, C. (2014). "Auto-secularización del pensamiento cristiano: una observación sociológica a las transformaciones estructurales y semánticas del ámbito religioso en la sociedad contemporánea”. Fondo Nacional de Desarrollo Científico y Tecnológico. http://w1.conicyt.cl/bases/fondecyt/personas/4/3/43624.html

Dockendorff, C. (2015). "Pretensiones normativas de la religión como problema. Una aproximación desde las teorías sobre secularización y diferenciación social de Habermas y Luhmann". Revista de Estudios Sociales 51: 36-49.

Dockendorff, C. (2016). "Variaciones religiosas en el cristianismo occidental y latinoamericano: Una observación desde la teoría de sistemas sociales". Revista MAD 34: 106-132. DOI 10.5354/0718-0527.2016.40617

Dockendorff, C. (2019). "Valores propios, recursividad y dimensión histórico-contextual de la comunicación: El fundamento operativo del fenómeno llamado "cultura". Revista MAD 40: 14-27. DOI: 10.5354/0718-0527.2019.54831

Drewermann, E. (2007). Atem des Lebens. Die moderne Neurologie und die Frage nach Got"t. Miami: Editorial Patmos.

Fediakova, E. (2007). "Religión, política, ciudadanía: cambio de paradigmas en las iglesias evangélicas en Chile postguerra fría". Revista Bicentenario revista de historia de Chile y América 2 (6) 71-98. https://dialnet.unirioja.es/servlet/revista?codigo=10896

Fediakova, E. (2012). "Saliendo del "refugio de las masas": evangélicos chilenos y compromiso social". En Religión, Política y Cultura en América Latina, editado por Christian Parker, 125-145, Santiago de Chile: IDEA Usach, ACSRM.

Foerster, H. von (1976). Objects: Tokens for (Eigen-) Behaviors. ASC Cybernetics Forum 8: $91-96$.

Foerster, H. von (2003). Understanding Understanding: Essays on Cybernetics and Cognition. New York: Springer.

Freston, P. (2012). "Las dos transiciones futuras: Católicos, Protestantes y Sociedad en América Latina". En Religión, Política y Cultura en América Latina, editado por Christian Parker, 77-95, Santiago de Chile: IDEA Usach, ACSRM.

Revista Cultura \& Religión Vol. XIII, 2019 № 2 (julio-diciembre)

Cómo citar este artículo: Dockendorff, C. y Romero, J. (2019). "Neurociencias y auto-secularización del cristianismo: resonancias en iglesias cristianas chilenas”. Revista Cultura \& Religión.13(2). pp. 1-29. 
Golombeck, D. (2014). Las neuronas de Dios. Una neurociencia de la religión, la espiritualidad y la luz al final del túnel. Buenos Aires: Siglo Veintuno.

Instituto Nacional de Estadísticas (INE). (2012). Censo 2012. Resultados XVIII Censo de población. Instituto Nacional de Estadísticas. www.cooperativa.cl/noticias/site/artic/20130425/asocfile/20130425190105/resultad os_censo_2012_poblacion_vivienda_tomosiyii.pdf

Latinobarómetro Opinión pública latinoamericana. (2017). Informe Latinobarómetro 2017. http://www.latinobarometro.org/latNewsShowMore.jsp?evYEAR=2018\&evMONT $\mathrm{H}=1$

Latinobarómetro Opinión pública latinoamericana. (2018). El Papa Francisco y la religión en Chile y América Latina. Latinobarómetro 1995-2017. www.latinobarometro.org/latNewsShow.jsp

Luhmann, N. (1991). Sistemas Sociales. Lineamientos para una teoría general. México: Alianza Universidad.

Luhmann, N. (2007). La sociedad de la sociedad. Madrid: Herder.

Luhmann, N. (2009). Sociología de la Religión. México D.F: Herder.

Lutz, A., Dunne, J., Davidson, R. (2006). "Meditation and the neuroscience of consciousness: An Introduction". The Cambridge Handbook of Consciousness, Edited by Zelazo P.D., Morris Moscovith y E. Thompson. Cambridge: University Press. http://www.transpersonlig.no/sbs/pdf/Dunne_Ch\%2019\%20Lutz\%20Dunne\%20Da vidson-1.pdf

Lutz, A., Slagler, H., Dunne, J., Davidson, R. (2008). “Attemtion regulation and monitoring in meditation". Trends Cogn Sci. 12(4): 163-169. doi: 10.1016/j.tics.2008.01.005

McNamara, P. (2009). The Neuroscience of Religious Experience. Cambridge: University Press.

Mardones, J. (1994). Para comprender las nuevas formas de la religión. Navarra: Verbo Divino.

Martínez-Salgado, C. (2012). El muestreo en investigación cualitativa. Principios básicos y algunas controversias. Revista Ciênc. saúde coletiva vol.17 no.3 Rio de Janeiro Mar. 2012. http://www.scielo.br/scielo.php?script=sci_arttext\&pid=S141381232012000300006

México: Editorial Grijalbo.

Mc Guire, M. (2008). Lived religion, faith and practice in everyday life. Oxford: University Press.

Newberg, A. (2010). Principles of Neurotheology. Farnham. Surrey: Ashgate Publishing.

Nogués, R. (2011). Dioses, Creencias y Neuronas, una aproximación científica a la religión. Madrid: Claret.

Nogués, R. (2013). Mujeres en la Iglesia. Madrid: Editorial Fragmenta.

Parker, C. (2005). "¿América Latina ya no es católica? Pluralismo cultural y religioso creciente". América Latina Hoy 41: 35-56. http://revistas.usal.es/index.php/11302887/article/view/2431

Revista Cultura \& Religión Vol. XIII, 2019 Nº 2 (julio-diciembre)

Cómo citar este artículo: Dockendorff, C. y Romero, J. (2019). "Neurociencias y auto-secularización del cristianismo: resonancias en iglesias cristianas chilenas”. Revista Cultura \& Religión.13(2). pp. 1-29. 
Olmos, A. L. (2017). “Otro catolicismo posible: institución, dios y agentes católicos en las experiencias biográficas de las fieles". Revista Cultura \& Religión. 11(1). pp. 4-22

Parker, C. (2009). "Education and Increasing Religious Pluralism in Latin America: The Case of Chile”, pp. 131-181. En Religious Pluralism, Democracy, and the Catholic Church in Latin America, editado por Frances Hagopian, Indiana University of Notre Dame Press. https://doi.org/10.1177/0094582X15623771

Parker, C. (2012). Religión, política y cultura en América Latina: nuevas miradas. Santiago de Chile: IDEA Usach, ACSRM.

Pontificia Universidad Católica de Chile \& Gfk Adimark. (2018). Encuesta nacional bicentenario. https://encuestabicentenario.uc.cl/wpcontent/uploads/2018/10/Resultados-Encuesta-Nacional-Bicentenario-UCGfkAdimark-2018-Cap\%C3\%ADtulo-Religi\%C3\%B3n.pdf

Ros, J. (2018). "Claves para una sociología de la experiencia religiosa en el ámbito católico". Revista Cultura \& Religión. Vol. 12(1). pp. 54-74.

Rossman, G., Wilson, B. (1985). "Numbers and words: Combining quantitative and qualitative methods in a single large-scale evaluation study". Evaluation Review 9 (5): 627-643. https://journals.sagepub.com/doi/abs/10.1177/0193841X8500900505

Rubia, F. (2014). La conexión divina: La experiencia mística y la neurobiología. Madrid: Editorial Planeta.

Rubia, F. (2015). El Cerebro Espiritual. Madrid: Editorial Fragmenta.

Sequeiros, L. (2012). Ciencia y Espiritualidad. Madrid: Bubok Ediciones.

Sequeiros, L. (2013). Ateos espirituales. Conversaciones en Tendencias 21.net. Madrid: Bubok Ediciones.

Varela, F. (2009). Dormir, soñar y morir: Una exploración de la consciencia con el Dalai Lama. Madrid: Gaia Ediciones.

Revista Cultura \& Religión Vol. XIII, 2019 № 2 (julio-diciembre)

Cómo citar este artículo: Dockendorff, C. y Romero, J. (2019). "Neurociencias y auto-secularización del cristianismo: resonancias en iglesias cristianas chilenas”. Revista Cultura \& Religión.13(2). pp. 1-29. 
Anexo 1

Características generales de los participantes del estudio

\begin{tabular}{|c|c|c|c|}
\hline Entrevistados & Descripción & Religión & $\begin{array}{l}\text { Grado de } \\
\text { resonancia }\end{array}$ \\
\hline Entrevistado 1 & Teólogo Laico & Católico & 1 \\
\hline Entrevistado 2 & Teólogo Laico & Católico & 2 \\
\hline Entrevistado 3 & Teólogo Laico & $\begin{array}{l}\text { Evangélico } \\
\text { /protestante }\end{array}$ & 3 \\
\hline Entrevistado 4 & Sacerdote & Católico & 4 \\
\hline Entrevistada 5 & Laica & Católica & 2 \\
\hline Entrevistado 6 & Sacerdote & Católico & 4 \\
\hline Entrevistado 7 & Pastor & $\begin{array}{l}\text { Evangélico } \\
\text { /protestante }\end{array}$ & 1 \\
\hline Entrevistado 8 & Laico & Católico & 4 \\
\hline Entrevistada 9 & Teóloga Consagrada & Católica & 4 \\
\hline Entrevistada 10 & Pastora & $\begin{array}{l}\text { Evangélica/ } \\
\text { protestante }\end{array}$ & 2 \\
\hline Entrevistado 11 & Teólogo & $\begin{array}{l}\text { Evangélico } \\
\text { /protestante }\end{array}$ & 2 \\
\hline Entrevistado 12 & Teólogo laico & Católico & 4 \\
\hline Entrevistado 13 & Laico & $\begin{array}{l}\text { Evangélico } \\
\text { /protestante }\end{array}$ & 2 \\
\hline Entrevistado 14 & Laico & Católico & 1 \\
\hline Entrevistada 15 & Laica & Católica & 1 \\
\hline Entrevistado 16 & Sacerdote & Católico & 2 \\
\hline Entrevistado 17 & Teólogo laico & Católico & 2 \\
\hline Entrevistado 18 & Teólogo laico & Católico & 2 \\
\hline Entrevistada 19 & Pastora & $\begin{array}{l}\text { Evangélica/ } \\
\text { protestante }\end{array}$ & 2 \\
\hline Entrevistado 20 & Laico & Católico & 2 \\
\hline Entrevistada 21 & Teóloga laica & $\begin{array}{l}\text { Evangélica/ } \\
\text { protestante }\end{array}$ & 2 \\
\hline Entrevistada 22 & Teóloga laica & Católica & 1 \\
\hline Entrevistado 23 & Laico & Católico & 3 \\
\hline Entrevistado 24 & Teólogo laico & Católico & 2 \\
\hline Entrevistado 25 & Laico & Católico & 2 \\
\hline
\end{tabular}

Fuente: Elaboración propia.

Revista Cultura \& Religión Vol. XIII, 2019 № 2 (julio-diciembre)

Cómo citar este artículo: Dockendorff, C. y Romero, J. (2019). "Neurociencias y auto-secularización del cristianismo: resonancias en iglesias cristianas chilenas”. Revista Cultura \& Religión.13(2). pp. 1-29. 